\title{
Taking ELF off the shelf: developing HE students' speaking skills through a focus on English as a lingua franca
}

\begin{abstract}
This paper explores how principles derived from English as a lingua franca (ELF) research (e.g. accommodation, strategic competence) can provide insights into the speaking demands of group work in Anglophone EMI settings which includes native speakers as well as non-native speakers. The paper maps data gathered through interviews with first year undergraduate students against Mercer et al.'s (2017) oracy framework. It shows that students draw on a combination of linguistic, cognitive, physical and social \& emotional skills, many of which align with ELF principles.

However, current frameworks of support for speaking demands in HE (EAP \& Academic Skills) lack focus on dialogic speaking, pay little heed to ELF findings and cater for native speakers and non-native speakers separately despite their needs being similar. The paper argues that a focus on ELF can contribute to the development of speaking support which sits at the centre of students' academic journey and encourages better interactions between native and non-native speakers.
\end{abstract}

\section{Key words}

Higher education, Group work, English as a lingua franca, Oracy, academic skills support, EAP

\section{Funding}

This work was supported by Bournemouth University [Research

Development Funding], the University of Surrey [Faculty of Arts and Social Sciences Pump-Priming Grant] and the University of Nottingham: [School of Pharmacy Research Fund]. 


\section{Introduction}

As active learning approaches, requiring active engagement rather than passive participation in the learning process (Prince, 2004), are moving into the HE mainstream, students are required to draw on complex speaking skills. This is particularly true for group work which is often a pre-requisite for a final assessed assignment (Doherty et al., 2011), but may also be part of HE teaching practice in seminars or tutorials. However, a large body of research (see Section 2) suggests that group work, in particular when characterised by linguistic and cultural diversity of its participants, can be fraught with task-related and interpersonal difficulties which are often rooted in language and communication.

Drawing on interviews with first year undergraduate students this paper thus explores students' perceptions of the speaking demands in group work, focusing on Anglophone EMI settings which include native as well as non-native speakers of English. Oral performance is much more transient and less tangible than written words on a page, and group work in particular includes less explicit scaffolding than lectures or seminars in which tutors tacitly model academic language (Duff, 2010; Basturkmen \& Shackleford, 2015). As a result, no detailed exploration of speaking demands exists so far, in particular for group work involving native as well as non-native speakers. The study addresses this gap and also explores to what extent these speaking demands align with the strategic repertoire described as typical for communication through English as a lingua franca (ELF).

The paper starts with a short review of the literature on group work in higher education. After a description of the methodology used for this study, the paper will draw on interviews with undergraduate students from four subject areas to map the speaking demands for group work against Mercer et al.'s (2017) oracy framework. The paper closes with an evaluation of universities' provision to develop students' speaking skills and a discussion of how integrating an ELF perspective can help develop this provision. 


\section{Literature review}

Group work in higher education settings has been investigated from two main perspectives: English as a lingua franca) on one hand and mainstream $\mathrm{HE}$ research on the other. In this literature review, we will compare and contrast the insights gained through both perspectives in order to shine light on how their methodological approaches and assumptions have contributed to an underappreciation of the speaking demands for HE group work. ELF research, conducted through the analysis of authentic audio or video-recorded interactions, is little known and reported in mainstream HE research. In academic contexts, the settings in which data have so far been collected are, in the vast majority, international (aka non-Anglophone) EMI (English as a medium of instruction) settings in which native speakers are rare.

The limited scope of this paper does not allow us to join in the debate about definitions of ELF in any detail. For the purpose of this paper, we will rely on Seidlhofer's (2011) description of ELF as

"an additionally acquired language system that serves as a means of communication between speakers of different first languages, or a language by means of which the members of different speech communities can communicate with each other but which is not the native language of either - a language which has no native speakers" (p. 146).

Thus, Seidlhofer promotes the view that ELF is a language whose specific properties need to be acquired. Various strategies help speakers negotiate meaning and relationships, including, for example, backchanneling, repair or explicit signposting of intent, structure, importance of contributions (e.g. Björkman, 2011a). These are part of speakers' general strategic competence through which comprehension between speakers is facilitated (Celce-Murcia et al., 1994), including both pre-emptive strategies (e.g. slowing down to accommodate to other speakers' perceived skills level) and reactive strategies through which problems in comprehension can be mitigated and addressed, such as asking specific questions to deal with perceived misunderstanding (see Dippold, 2015 for a summary of ELF strategies in spoken academic classroom talk).

Hua (2015) uses the term 'Negotiation' - with a capital 'N' - to describe 
ELF speakers' collaborative and cooperative efforts, extending the term from the linguistic domain (negotiation of meaning as identifying and resolving communicative breakdowns, cf. Ellis, 2003, p. 346) to also include negotiating cultural frames of reference, differences between which can interrupt the flow of interactions. In addition, ELF research specific to group interaction also found the cooperative principle in evidence in participants' efforts to create and maintain rapport. Toomaneejinda \& Harding (2018) showed that participants in ELF academic group discussion used a wide range of strategies to express disagreement, including shift of focus, turn-management practices and use of gaze. Komori-Glatz (2018) demonstrated that high levels of trust supported the ability to disagree and challenge one another. Additionally, joking, talking about shared interests, exploring others' cultural background and "letting pass" strategies (Firth, 1996), the latter describing instances in which inaccurate language use is not flagged up, facilitate intercultural team work in HE (Komori-Glatz, 2017).

Whilst ELF emphasizes cooperation, research on HE group work published in mainstream HE journals takes a less optimistic perspective. Research from this tradition focuses on students' perceptions of what is often called 'international group work' and investigated through interviews or focus groups, in countries in which English is a majority language and with groups which consist of a mix of native and non-native speakers or home and international students respectively.

This body of research suggests strongly that students perceive group work as highly problematic from an academic and an interpersonal perspective. Soetano \& McDonald (2017) show that obstacles in group work derive from relational, leadership, management, and task-related domains, and that these obstacles are increasing as the task progresses to completion. Studies focusing specifically on international group work suggests that students prefer working in groups in which they share a cultural background with peers (Cathart et. al., 2006; Elliot \& Reynolds, 2014; Ippolito, 2007; Volet \& Ang, 1998). Others report evidence of negative stereotyping and 'othering' of international students (Gabriel \& Griffiths, 2008; Robinson, 2006; Turner, 2009). In addition, a quantitative study by Spencer-Oatey \& Dauber (2017) found that students from the UK were not only less positive than Chinese and other overseas students about a 
possible enriching effect of group work on their experience, but also expressed more doubts about the challenges of such group work contributing to their 'global graduate' skills.

However, the research also emphasizes that specific speaking skills are essential to succeed, not only in university group work, but also in future life and employment, in particular in (international) group work (Robles, 2012). Popov et al. (2012) assert that "communication is an essential tool by which group members organise their work and cooperate with one another" (p. 305) and subsequently show that insufficient language and communication skills were seen as the greatest challenges. In a study on student experiences of group work in a tourism context (Hassaninen, 2006), communication was considered to be one of the most significant group work challenges. Lack of formal leadership was also identified as a major obstacle, with likely roots in, and implications for spoken communication practices. In addition, students reported difficulties in building interpersonal relationships due to a lack of shared humour (Elliot \& Reynolds, 2004; Gabriel \& Griffiths, 2008; Ippolito, 2007) or communication difficulties caused by a perceived lack of language competence by international students (Montgomery, 2009). Home students were also shown to have negative views of international varieties of English (Dunne, 2009; Peacock \& Harrison, 2009). Hall \& Buzwell (2012) argue that a lack of communication skills is also one of the main reasons for 'free-riding', aka not contributing to the group task adequately, as "international students may be doubly tasked with the project requirements as well as communication issues" (p. 39). Given the differences in methodological approaches - one which derives its insights from the analysis of authentic data, the other one which focuses on perceptions and opinions - the differences in the stances between these two research traditions are perhaps not surprising. In addition, despite admitting the possible normative influence of native speakers in interpersonal encounters, research in ELF has so far underappreciated or even glossed over the role of native speakers in the interpersonal dynamics of educational encounters. For example, Mauranen (2012) openly states that "interactions where native speakers are the majority in a group situation [...] are of marginal interest in investigating ELF" (p. 9). Baker \& Hüttner (2017) in a study on conceptualisations of English in different EMI settings, say with respect to the results from the UK that 
"native like/standard English was seldom overtly viewed as a target of these programmes by participants (although, with the caveat that policy documents appeared more prescriptive). It has to be remembered, however, that at the UK site, this study explicitly excluded home students, who might well have a more normative endorsement of native standards, or a negative view of international students' English" (p. 512).

Given the insights gained through studies on perceptions of group work in which native speakers did indeed express negative views of non-native varieties of English (as outlined above), the lack of appreciation of the normative influence of native speakers represents an important oversight. Also, in light of the power relationships between native and non-native speakers and the prevailing nativespeakerdom (Ryan \& Viete, 2009) and nativeculturedom (Dippold, 2013) identified for Anglophone settings, the general cooperativeness attributed to ELF speakers may not apply in English majority education settings. Moreover, Björkman (2011a) also warns that more homogenous groups of speakers (i.e. those including a higher number of native speakers) are less likely to make use of the strategic repertoire mentioned above.

These oversights, described by Blai-Ward (2017) as an "assumption, tacitly underpinning English as a Lingua Franca (ELF) Research, that ELF should be discussed with reference to non-Anglophone countries" ( $p$. 25) explain, to some extent at least, the differences in the insights gained through ELF and HE research on group work. They can also explain that neither the role of ELF principles in group work in Anglophone settings nor the needs of native speakers in the process of creating mutual understanding through language, have yet been sufficiently appreciated. The mapping exercise conducted in this paper to investigate students' perceived speaking demands for group work will address these issues. 


\section{Methodology}

\subsection{Objectives and Research Questions}

The overall aim of this paper is to discuss how co-curricular student support for speaking skills in HE group work, in particular in Anglophone EMI environments which include native as well as non-native speakers, can be further developed. To this end, the paper investigates first year undergraduate students' perceived speaking demands in HE group work and explores where these demands align with the cooperative and strategic strategies proposed by ELF research (see Section 2). These objectives can be summarized in two research questions:

1.What are students' perceived speaking demands for HE group work in Anglophone EMI environments?

2.To what extent do these speaking demands align with the strategic repertoire identified by ELF research?

\subsection{Participants and sites}

The research was conducted at four different university sites in the UK, each representing a different discipline of study (table 1). All have a diverse intake of students. The first phase of interviews was held during the first four weeks of the academic year 2016/17. Students participating were re-invited to a follow-up interview in the final weeks of the second semester to gain an updated understanding of their educational development and perceptions. This paper will draw on self- reports from both phases of data collection. Full ethical approval was received for the study and students informed via participation information sheets and consent forms of the nature of the study, their participation and that all data would be anonymised.

Participants were recruited from compulsory first year modules in courses cognate to the academic fields represented by each of the investigators. They were invited through a short introductory talk in an early session, which was then followed up by e-mail invitations and individual 
arrangements through email. A total of 70 interviews were conducted, with 45 from the first phase and 25 from the second phase of data collection (table 1). This paper is drawing on both interview phases.

Table 1: Data by institution and phase of the project

\begin{tabular}{|l|l|l|l|}
\hline Institution & $\begin{array}{l}\text { Discipline of } \\
\text { Study }\end{array}$ & $\begin{array}{l}\text { Phase 1 (Oct- } \\
\text { Nov 2016) }\end{array}$ & $\begin{array}{l}\text { Phase 2 (Mar-Apr } \\
\text { 2017) }\end{array}$ \\
\hline Institution 1 & Media Studies & 4 & 4 \\
\hline Institution 2 & Business Studies & 15 & 9 \\
\hline Institution 3 & Pharmacy & 10 & 5 \\
\hline Institution 4 & Humanities & 16 & 7 \\
\hline
\end{tabular}

The students interviewed represent a mix of native languages, individual language learning histories and experiences of interacting with speakers speaking different languages or other varieties of English. Some of the UK 'home' students were from ethnic minorities, whilst some international students had received high school and college education in the UK. For the purpose of this paper, we will rely on students' selfidentification as native or non-native speakers or representatives of particular nationality, allowing us to place the focus on the speaking demands.

\subsection{Data analysis}

Interviews were audio recorded and transcribed verbatim. When students made reference to other group members by name, we replaced these with pseudonyms. References to speaking demands were then mapped against Mercer et al.'s (2017) oracy framework. Developed initially as an assessment tool for a project with a secondary school in which students were provided with targeted oracy skills training, the framework includes four skills domains, each of which has a number of subcategories, as shown in table 2. 
Table 2: Oracy skills dimensions (based on Glossary of Skills, n.d.)

\begin{tabular}{|c|c|c|}
\hline $\begin{array}{l}\text { Oracy skills } \\
\text { dimensions }\end{array}$ & Subcategories & Examples \\
\hline \multirow[t]{2}{*}{ Physical skills } & Voice & $\begin{array}{c}\quad \square \text { fluency and pace of } \\
\text { speech } \\
\square \text { tonal variation } \\
\square \text { clarity of pronunciation } \\
\square \text { voice projection }\end{array}$ \\
\hline & Body language & $\begin{array}{l}\square \text { gesture and posture } \\
\square \text { facial expression and } \\
\text { eye contact }\end{array}$ \\
\hline \multirow{4}{*}{$\begin{array}{l}\text { Linguistic } \\
\text { skills }\end{array}$} & Vocabulary & $\square$ appropriate vocabulary choice \\
\hline & Language Variety & $\square$ register $\square$ grammar \\
\hline & Structure & $\square$ structure and organisation of talk \\
\hline & $\begin{array}{l}\text { Rhetorical } \\
\text { techniques }\end{array}$ & $\begin{array}{l}\square \text { rhetorical techniques, e.g. metaphor, } \\
\text { humour, irony and mimicry }\end{array}$ \\
\hline \multirow{2}{*}{$\begin{array}{l}\text { Cognitive } \\
\text { skills }\end{array}$} & Content & $\begin{array}{l}\square \text { choice of content to } \\
\text { convey meaning and intention } \\
\square \text { building on the views } \\
\text { of others }\end{array}$ \\
\hline & $\begin{array}{l}\text { Clarifying and } \\
\text { summarising }\end{array}$ & $\begin{array}{l}\square \text { seeking information and clarification } \\
\text { through questions } \\
\square \text { summarising }\end{array}$ \\
\hline
\end{tabular}




\begin{tabular}{|l|l|c|}
\hline Self-regulation & $\begin{array}{c}\square \text { maintaining focus on task } \square \text { time- } \\
\text { management }\end{array}$ \\
\cline { 2 - 3 } & Reasoning & $\begin{array}{c}\square \text { giving reasons to } \\
\text { support views } \\
\square \text { critically examining } \\
\text { ideas and views }\end{array}$ \\
\hline
\end{tabular}

\begin{tabular}{|c|c|c|}
\hline & $\begin{array}{l}\text { Audience } \\
\text { awareness }\end{array}$ & $\begin{array}{l}\square \text { taking account of level of } \\
\text { understanding of the audience }\end{array}$ \\
\hline \multirow{3}{*}{$\begin{array}{l}\text { Social \& } \\
\text { Emotional } \\
\text { Skills }\end{array}$} & $\begin{array}{l}\text { Working with } \\
\text { others }\end{array}$ & $\begin{array}{l}\square \text { guiding or managing the interactions } \\
\square \text { turn-taking }\end{array}$ \\
\hline & $\begin{array}{l}\text { Listening and } \\
\text { responding }\end{array}$ & $\begin{array}{l}\square \text { listening actively and responding } \\
\text { appropriately }\end{array}$ \\
\hline & $\begin{array}{l}\text { Confidence in } \\
\text { speaking }\end{array}$ & $\square$ self-assurance $\square$ liveliness and flair \\
\hline
\end{tabular}

The oracy framework was chosen to provide an analytical framework for this paper for a number of reasons. Whilst it had originally been developed in an effort to assess spoken language, and recognise the centrality of spoken language for educational success at secondary level, Heron (2019) has made a strong case for its use as an accessible assessment and feedback tool in higher education. Additionally, Mercer et. al. (2017) confirm that the oracy framework is informed by models of communicative competence (e.g. Celce-Murcia et al., 1994) which include reference to strategic competence and thus was considered suitable for the secondary focus on ELF.

Given the original focus of the project on students' experiences of settling into university, the oracy framework was not originally part of the interviewing strategy, and the interview guide for the semi- structured interview did not include an explicit question about speaking demands in 
group work. Instead, these issues emerged from further questioning, in particular in response to an interview question exploring experiences of working with others, and challenges faced in these instances. Students also referred to group work in other parts of the interview, for example when asked about their best and worst experiences at university. In the vast majority of cases, students discussed group work as an activity underpinning tasks which had a defined output, such as an assessed project or presentation. The fact that students referred to issues of oracy consistently despite not being explicitly asked about them is thus particularly compelling, showing that they perceive of oracy issues to be a possible impediment to success.

All references to speaking demands for group work were mapped against the oracy framework through researcher interpretation when the content of their statements was seen to match the framework dimensions and subcategories (see table 2). In order to get a sense of the degree of necessity and importance of various demands, a numerical count of 'mentions' of each of the subcategories was conducted. Associations

between different oracy domains and subcategories were also established by counting extracts of data which were coded into more than one domain or subcategory. The quantitative results will be presented at the beginning of the results section below and then subsequently illustrated with extracts from the interviews. 


\section{Results}

\subsection{Quantitative results}

An initial quantitative count of the instances in which specific speaking demands were referred to provides an indication of the perceived importance of each of the four main oracy domains and their associated components for group work. The figures of the subcategories do not add up to the total of the main domains as many speaking skills references were double-coded.

Table 3: Speaking demands in group work

\begin{tabular}{|c|c|c|}
\hline \multicolumn{2}{|l|}{ Physical } & 4 \\
\hline & Body language & 0 \\
\hline & Voice & 4 \\
\hline \multicolumn{2}{|l|}{ Linguistic } & 15 \\
\hline & Vocabulary & 2 \\
\hline & Structure & 3 \\
\hline & Rhetorical techniques & 4 \\
\hline & Language variety & 11 \\
\hline \multicolumn{2}{|l|}{ Cognitive } & 28 \\
\hline & $\begin{array}{l}\text { Clarifying and } \\
\text { summarizing }\end{array}$ & 2 \\
\hline & Audience awareness & 7 \\
\hline & Self-regulation & 9 \\
\hline & Reasoning & 10 \\
\hline & Content & 10 \\
\hline
\end{tabular}




\begin{tabular}{|l|l|l|}
\hline \multicolumn{2}{|l|}{ Social \& emotional } & 71 \\
\hline & Listening and responding & 6 \\
\hline & Confidence in speaking & 8 \\
\hline & Working with others & 61 \\
\hline
\end{tabular}

Table 3 shows that there is a clear imbalance in the number of mentions of specific speaking demands. The 'social \& emotional' domain clearly dominates, led by 'working with others'. This is followed by items from the cognitive and then the linguistic domain, with issues relating to the language variety being at the forefront here. Issues relating to physical production of language are not discussed by the students very frequently.

An additional analysis of items relating to group work which were double-coded allows us to see which categories have strong associations (table 3).

Table 4: Speaking demands mapped onto oracy: Code overlap

\begin{tabular}{|l|l|}
\hline Physical - Social \& emotional & 2 \\
\hline Physical - Linguistic & 3 \\
\hline Cognitive - Physical & 3 \\
\hline Cognitive - Linguistic & 5 \\
\hline Social \& emotional - Linguistic & 11 \\
\hline Social \& emotional - Cognitive & 18 \\
\hline
\end{tabular}

Table 4 shows that associations between the social \& emotional and linguistic as well as the social \& emotional and the cognitive domains were particularly strong, followed by the cognitive - linguistic nexus. We 
will explore these links further later on, after illustrating these domains through examples from the data set.

\subsection{Physical domain}

In the category of physical language production which, overall, appears to be of little importance to students, all references coded refer to 'voice' and, within this domain, fluency and pace on one hand and clarity of pronunciation on the other. In (1) below, the student discusses a 'language barrier', which she acknowledges was exacerbated by inadequate pacing of her own delivery.

(1) We just straight off said 'do you mind doing this?' the girl was like 'that's fine, I just misunderstood'. We weren't like 'you've done this wrong', we just said 'did you not understand? We can go through it again'. So we went through it again and she was fine and apologies and the next day had it [inaudible]. So it wasn't a problem, I think sometimes, you've probably noticed that I speak fast, [inaudible]. [...] I don't know if it was just being blind to it, but she addressed it straight away and we obviously 'we're really sorry, didn't realise' and we've changed it. We've try speaking a bit slower.

Example (1) also suggests that the student only became aware that their delivery was too fast to be processed when the other group member explicitly expressed problems in understanding. This allowed the students in the group to slow down to enable the interlocutor to follow the talk. Slowing down is a strategy which is part of an ELF repertoire of accommodation / comprehension- facilitating skills. The next example exemplifies the detrimental effect when interlocutors do not accommodate:

(2)

Yeah,thestrongaccent, theyspokeveryfast,youknow? Andtheyspeakreallyfast andthewords I was - you know? Maybe one or two gi-words get [inaudible] but I can't judge what was a full sentence or what they said.

This student, who in the interview described himself as Indian, describes talk by group members as less intelligible when it was delivered too fast. A strong local accent - which is also part of 'voice' in the oracy 
framework - exacerbated these problems.

\subsection{Linguistic domain}

\subsubsection{Vocabulary}

There are only two references to use of vocabulary in the data. Both of them relate to techniques for ensuring that the lexical choices are comprehensible:

(3) Sometimes I just don't know what it is in English and I just tell my friends. I'm like, okay, it's when you feel like this this this and then they're like, oh, okay [...]. And it's sometimes really funny because like when you can't describe the word, you just make like...you know, like, vroom or you make a sound and then they just laugh and you're, like, oh wow.

Here the student reports difficulties arising from themselves or others not knowing particular lexical items in English, and provides an example of using sound to paraphrase words. Paraphrase is also part of the strategic competence necessary to compensate when there is a danger of communicative breakdown, and therefore part of an ELF repertoire of skills (see Section 2).

\subsubsection{Structure}

In the oracy framework, efforts for structuring and organising the talk are described as serving the purpose of making talk relevant, clear and comprehensible to the audience. Thus, structuring the talk appropriately seems to serve mainly the purpose of negotiating meaning. The next example however suggests that interpersonal rapport may also be at stake:

(4) Even though it's a group, uh-huh. But everyone's sort of listening to everybody else. And I- and I think the only- the only thing is, is that obviously, I take into consideration now wh-what other people's - if people are struggling or people's $i$ - the people's ideas. Instead of just saying 'no, no we 're not doing that', I'll explain why I don't think we should do it. Where I think I-I lacked possibly before having to explain 
things out where now I need to explain to people this is- this is why I don't think it's a good idea. Where before and it's your own business, you just say 'no. We're not- I'm not doing that.'

In (4), the student reports that, by offering an explanation, he has enabled the group discussion to continue smoothly, causing no one to become offended and lose face. Thus, the principle of cooperativeness identified for ELF seems to apply here, with links to the social \& emotional domain evident.

\subsubsection{Rhetorical techniques}

The oracy framework suggests that rhetorical techniques enhance meaning and create rapport. Humour is one such technique and mentioned in two out of four instances:

(5) I wouldn't say it was just me but like I guess, because I knew another friend so I was doing something and my friend just suddenly joked and then like everyone just laughed. I forgot what it was but I just remember everyone laughing and I put a comeback and then I was like 'please, I'm from a science background, I know my Physics' and they were like 'you're in Business School now' so like everyone just laughed and slowly we just put in our input and then. [...] Yeah the humour broke the ice.

In (5), the student describes an instance of group work in which the individuals within the group were previously unfamiliar with one another, but in which mocking reference to each other's subject areas and how they might contribute to the project broke the ice between group members. Whilst not at the core of an ELF repertoire, humour can be considered to be an important technique for facilitating the rapport and interpersonal dimension of group work.

\subsubsection{Language variety}

The vast majority of items mapped onto the linguistic domain of the oracy framework relate to issues of language variety, and within that assessments of accuracy and effectiveness of non-native varieties of 
English. These descriptions are often framed positively, which appears to be an effort to appear un- prejudiced. This is evident in (6):

(6)

Sometimesit 'stheydon 'tfeelasconfident.Imean,ifyouactuallyaskthemaquesti on, theirEnglish is absolutely superb. You know, it's quite surprising how, like, fluent some of them are [chuckles]. But I think sometimes they're nervous- too nervous to really contribute. And sometimes you do have to ask them questions and you do have to somehow take the information from them rather than ha- expecting them to give it to you. You have to really challenge some people to give you information.

This student evaluates non-native speakers' English as 'superb' and 'fluent', but nevertheless goes on to talk about the difficulties of asking the right questions to allow non-native speakers to contribute. Whilst this facilitates the ability to negotiate meaning, it also requires complex speaking skills including questioning techniques.

Discussions of language variety, in particular of non-native varieties, are often associated with the social \& emotional domain.

(7) It became very challenging that there was also a young Chinese girl who didn't speak the language very well. So we got four or five people and two of them you can't really work with. It makes it very difficult to assign the camera and direct it. It's very challenging. [...]. When it's her talking, it's pretty good English. And it's such a hard thing to understand, they talked to me. They looked slightly confused. You think, "Do you know what we 're saying? Do I have to show every word?" And they don't know if they know. It's really difficult, isn't it?

In this example, the student, who identifies himself as a native speaker of English, first suggests that the Chinese group member 'didn't speak the language very well', but then goes on to say that 'when it's her talking, it's pretty good English'. It subsequently becomes apparent that the interactional issues described here seemed to arise primarily from not getting sufficient amount of listener responses indicating understanding, and of not knowing exactly how to adapt one's own delivery to support the listener, i.e. what kind of accommodation strategies should be used. This strongly suggests that mutual engagement is essential for facilitating 
comprehension, with listeners needing to provide feedback on whether understanding has been achieved, and what adaptations are necessary to facilitate comprehension.

\subsection{Cognitive domain}

\subsubsection{Clarifying and summarizing}

Seeking information and clarification through questions, as referred to in (7), is also part of the 'clarifying and summarizing' subcategory of the cognitive domain. Only one additional example of 'clarifying and summarizing' was found in the data:

(8) Literally anything, so if we ever had a question. We have projects to do, and with the first project it was so unclear what we had to do, so unbelievably unclear. So if we asked a question, the tutor would respond with how can you take that further? We were like, sorry what? That wasn't an answer to my question. We were asking you if this is correct, and he just said, how can you take that further? He was literally on repeat.

The respondent in (8) refers to a situation in which students tried to clarify group work requirements with a tutor. However, they always received the same answer, which was not seen to be helpful. This may suggest that the students lacked ability in rephrasing the question to clarify its meaning, but could also be suggestive of the tutor's lack of accommodation skills which, if present, might have allowed him to scaffold the students' questions, clarify meaning and subsequently give a more appropriate answer.

\subsubsection{Audience awareness: taking account of the level of understanding of the audience}

In the original oracy framework, audience awareness is clearly understood in cognitive terms, as "judging what listeners already know, or do not know, about the topic being dealt with" (Glossary of skills n.d.). However, the students in this investigation describe it as awareness of the degree of linguistic understanding of others, as previously shown in examples (1) and (7), but also (9): 
(9) The young Chinese girl, that was very difficult. I mean I wouldn't say I actually dealt with it particularly well. Because when you speak, you obviously talk to the person. You don't quite know how much they're understanding. And you don't want to patronise them and like talk slowly like really slowly and that. So it was difficult, you have to do the same like, try to say it slowly and clearly and give a smaller task.

Here we see the student admitting to difficulties in gleaning how much the other person understands. What is interesting is that the student does not discuss these issues only in terms of the specific accommodation strategies used - speaking more slowly and more clearly - but also in terms of the possible social \& emotional impact on the listener, in this case the danger of being patronising. The latter is indeed a concern which has previously been described in other ELF research (e.g. Margić, 2017). This example thus illustrates the link to the social \& emotional domain with concerns for rapport and face and suggests that interpersonal issues need to be considered.

\subsubsection{Self-regulation}

Example (10) confirms how walking the tightrope of interpersonal rapport management may impact the ability to maintain focus on the task through self-regulation.

(10) Time-management wasn't good. I felt that I had regained control towards the end more. When we had to write out on a sheet and I couldn't write fast enough because everyone was talking over each other. I singled out people to get it written down. That was a good way to do it. There were shy people that wouldn't talk because everyone was going to talk. I was one of the people talking and maybe should have looked at it a different way.

In (10), the student talks about a group task over which he sensed having lost control due to unregulated turn-taking ('talking over each other'), but regained a sense of control by nominating group members to speak. However, shy group members still wouldn't contribute to the task, which suggests that additional scaffolding may have been required and emphasizes the complexity of the speaking demands to ensure successful task completion. 


\subsubsection{Reasoning}

The category of 'reasoning' refers to ways of justifying points of view.

(11) I'm I'm really good at communicative- communicating with other people, but for a group work, for teamwork I think I'm not very good at it because I don't like explaining my thoughts to other people. I enjoy more working on my own because I - I don't like depending on others and yeah.

In (11), the student discusses their problems with reasoning in a group task, suggesting that she harboured a dislike of 'explaining my thoughts to other people'. Later on, they go on to explain that this is linked to an aversion to 'depending on others', suggesting that the interactive nature of group interaction makes the act of reasoning more difficult and less predictable.

\subsubsection{Content}

The final category on the cognitive domain and the one most frequently referred to in this data set is that of 'content', which includes 'choice of content' and 'building on the views of others'.

(12) I think for some people it was difficult going from being at school working on your own to having people to rely on, but everyone kind of got the hand of it towards the end. And I, like I got better at it as I went through. [...] I think I got more tolerant (laughter) because I was like, I have this tendency when someone's like "Right okay, what should we do with this problem?" and I'm like "Right here's the solutions." And everyone's like. "Yeah, great, do it," and then someone else was like, "No, let's do it this way", and I am like "No no, I have already said something, this is...". It's just like with ideas, they are becoming a baby at some point. And I got better at doing that because I do find that hard at the beginning. [...] My course [...] had a sort of session on the importance of kind of collaborating and the importance of like another people pitching and you know not being afraid to ask for help. [...] And that was a bit of learning curve for a lot of people. So the course do help with kind of adapting to that which was quite helpful.

Example (12) suggests that co-constructing the content of talk in groups is 
a skill that needs to be developed, in particular when it is a relative novelty to students just out of school. It also places complex demands on the speaker, involving other key areas from the cognitive and social \& emotional domains, such as turn- taking, reasoning, clarifying and summarizing.

\subsection{Social \& emotional domain}

\subsubsection{Listening and responding}

The least frequently referred to subcategory of the social \& emotional domain is 'listening and responding', which includes both active listening and giving appropriate responses. It arose six times in the data set. In the example below, a student discusses integrating a Polish student into the group.

(13) Well [sighs] - I tell you, she- she taught me that- to listen. I'm not usually listening. And this is something that I didn't realise neither. I'm not a very good listener. I hear but I don't listen. [...] Through Alina, that's what she's given me. Absolutely. Because I've-I have to listen to what she says [...] Where with Alina, she 'll say 'I don't understand it' and she really doesn't-doesn't understand it. So, it's- it's listening and saying 'right-right, okay. You don't understand that. So, how are you gonna understand it? What can we do? How are you gonna - what are you gonna - how are we gonna get you to understand this?' So, I think my tolerance as well is much greater now, working with Alina, than what it was if I'd just been in a group without Alina.. So, she's-she's benefitting me quite a lot.

The response by the student in (13) suggests that having the non-native speaker as a group member has improved not only their listening skills, but also their ability to respond appropriately, in this case by using comprehension checks, which are part of the ELF repertoire. Importantly, this informant reports the experience of group work with a non-native speaker having a wider-reaching effect, allowing them to develop skills that can be carried over to other contexts.

\subsubsection{Confidence in speaking}

Confidence in speaking, which is also part of the social \& emotional 
domain, was referred to eight times in the data set. The same student as in (13) above establishes a link between confidence, group members' willingness to accommodate and task success:

(14) Her English is very good but she has a personal - I think she has a personal issue that she thinks she doesn't communicate well but she-I think she does communicate well. So, I think she just-just lacks confidence. And-and she reads - yeah, her English reading's good, English writing's good and - but I think she le-you know, she lets people a little bit overpower her sometimes. So, I'm very aware with Alina that she needs - 'cause some of the girls are slightly intolerant to her, that she's not fast enough, that she's not - which I thought I was- that is my character, if I'm honest. But not with Alina. Because I think, you know, she just needs help. She needs he-and she needs to feel-out of everybody, she needs to feel that she's part of the team, I think. Which is ironic because I think [inaudible] things, it doesn't match. It doesn't match what she put in her [inaudible] because she's- she's the coordinator, I think it was, when - and it's-she's not at all. But I-but now we've worked together a couple of weeks and we talk in differentdifferent ways.

Here, this student links her group mates' attitudes towards the Polish group member Alina, in particular their lack of willingness to use accommodation strategies, to Alina's own lack of confidence. However, she subsequently suggests that the group's collaboration over a number of weeks has changed things ('we talk in different ways'), including her own ability to use comprehension checks (see example 13). This suggests that speakers may well be able to develop the ability to accommodate to other group members during the course of group work, but only if they possess a basic degree of awareness of communication practices and their effect.

\subsubsection{Working with others}

Given previous observations, it is perhaps not surprising that, within the social \& emotional domain, most comments can be mapped onto 'working with others'. This includes, on one hand, taking turns and allowing others opportunities to speak: 
(15) We were given a problem about Marks and Spencer's. We had to look at how we would fix it in terms of marketing, innovation and new management. The communication was off, and we clashed, like a few people would be talking over each other constantly then go silent, talking over each other and then go silent. It was a bit mish-mashed.

This student's description of their group's communication style as 'mishmashed' indicates the group's problems in managing who contributes what and when. Managing interactions of course links back to other categories of oracy previously discussed, in particular active listening, self-regulation, structure and organisation of talk. Hence, it is also part of the collaborative attitude through which ELF interactions have been described.

Our final example in this section is an example of an attempt to guide and manage interactions, which is also part of 'working with others'. It shows that, when actively raised, interpersonal issues with other group members can often be resolved:

(16) And then when we got put into our teams, most of us got along well but there was a bit of a clash between two of them. There was a bit of rivalry there. [...] It was just the way they interacted with each other. You could tell one wanted to have one over the other and stuff. And one didn't like what the other was saying and you could tell. You could tell there was some tension between them. [...] I did bring it up once, to the guy that I was closer to, who has involved. Then after that I noticed a difference. I don't know if they just didn't notice it. And then once he realised that there was some sort of rivalry going on, he tried harder to get along with him.

The report here shows how issues in working together were collectively resolved, but finding this resolution was reliant on a group member actively raising the issues ('I did bring it up once'). This may suggest that, in many cases, participants in group work may not be aware of how their communication practices contribute to group dynamics. However, the students' report of improving relationships after the intervention also suggests that interactions can be successfully managed when speakers make a conscious attempt to do so. 


\section{Discussion}

\subsection{Speaking demands in group work - Summary}

This paper has set out to answer the following two research questions, the main insights into which are summarised below:

$R Q$ 1: What are students' perceived speaking demands for HE group work in Anglophone EMI environments?

In answer to RQ1, our analysis has found that the speaking demands for group work perceived by students cover all dimensions and most subcategories of the oracy framework. Speaking demands relating to the social \& emotional domain appear to be particularly important for group work success, followed by those from the cognitive domain, such as clarifying and summarizing, staying on task, building on the views of others. Permeating both domains is a strong emphasis on strategic skills which allow for the interlocutor to follow the interaction. This will be further explored in relation to RQ2.

Despite the linguistic domain being relatively unimportant overall, the analysis identified a strong link with the social \& emotional domain, in particular owing to a number of negative attributions towards non-native language varieties. However, we have also shown that, if non-native speakers were seen to be cooperative in flagging up misunderstanding, these negative attributions tended to be quickly qualified, which suggests that the willingness to engage in a mutual and negotiated process of achieving understanding is much more important than using a variety of language which conforms to native norms of accuracy.

When a group made no efforts in making allowances for spoken language performances diverging from a native norm however, the psychological impact on non-native speakers was high, as the student in (17) suggests in relation to mocking for his accent or body language during a group presentation:

(17) The- the- you know, it was a bit awkward when I was presenting. Everyone in my group was laughing. I don't know. Because it was my accent, it was my body language, it was something else or maybe they were not laughing at me. But in that group, I was standing and everyone 
is laughing so, you know, I do- [...] So, I- I- my confidence was a bit shaken and I- literally, I can't [inaudible]. I need to be with them. Yeah. So that I can get rid of them. I- that wasn't the position in that- that moment, you know? Because I was literally shaken.

Moreover, we have also shown that the social \& emotional domain interplays strongly with the cognitive domain. When individuals try to argue their points and agree on a course of action in a group, the potential for interpersonal disturbances is obvious, requiring skills in regulating the talk and remaining on course with the task (10), avoiding offence as a result of the reasoning strategies used (11) and co-constructing the argument (12). Underpinning these are the ability to regulate turns in talk and adequate skills in listening and responding. The latter in particular are strongly linked to strategic competence, allowing speakers to facilitate comprehension (see Section 2).

$R Q$ 2: To what extent do these speaking demands align with the strategic repertoire identified by ELF research?

As discussed earlier (see Section 2), ELF research generally suggests that speakers draw on a wide strategic repertoire to negotiate meaning and rapport. However, we have previously discussed the possible bias inherent in the insights derived from ELF research, as the majority of studies derive from settings in which there is no native speaker gatekeeping. Previous research suggests that the Anglophone environment in itself provides a normative frame for the encounter (Dippold, 2013; Ryan \& Viete, 2009).

RQ 2 thus aimed to identify how the speaking demands discussed align with an ELF repertoire of strategies. We were able to identify evidence of strategies throughout the data set by which speakers negotiate meaning and relationships. Most notable were references to adapting the speed of delivery (physical domain), accommodating vocabulary choices to the abilities of the interlocutor (linguistic domain), clarifying meaning, taking account of the degree of linguistic understanding of the audience (cognitive domain), active listening and interaction management (social \& emotional domain). Equally importantly, there was evidence from across the data set showing that humour, efforts for clarifying meaning, conscious attempts to avoid offence and the ability to openly raise and 
discuss communication issues, support collaborative group interactions, which links strongly with the ELF emphasis on collaboration and cooperation.

In addition, statements outlining the importance of interlocutor-awareness permeate the entire data set and derive, in the vast majority, from native speakers of English. In many cases, these statements are made in reference to interactions with other native speakers or in homogenous groups, suggesting that interlocutor awareness and the specific speaking demands associated with it are relevant even when there are only native speakers involved in an interaction. We will discuss implications from this in Section 5.2.2.

Notably, these insights make the home student / native speaker appear in a much more positive light than the existing body of literature on group work in Anglophone higher education would suggest. They show that many native speakers may place importance on communicating effectively and on creating rapport through communication. However, at times, speakers may lack the ability to carry these good intentions through into practice, as shown in example 7.

This clearly suggests that there is the case to be made for transporting ELF principles from non-Anglophone EMI into Anglophone EMI and integrating ELF principles into mainstream student support initiatives.

\subsection{ELF and oracy in higher education: frameworks of support}

\subsubsection{ELF in the oracy skills framework}

In this section, we aim to address how the development of ELF skills in higher education can be practically scaffolded. We start by scrutinizing the oracy framework which has been used for the mapping exercise of speaking demands in group work.

This analysis has shown that the oracy framework, as it currently stands, needs further development in order to accommodate the notion of ELF communication and its related skills, in particular if it is to be used to support teaching and development in Higher Education. The oracy framework includes the sub-category of 'audience awareness' (under the cognitive domain), which is concerned primarily with the ability to tailor 
the content of the talk to others' level of knowledge. Accommodation skills in the ELF sense however go further, describing the ability to use language that is appropriate to others' level of linguistic understanding. One student, when asked in the interview what they had learned from working with diverse groups, answered that the ability to accommodate to the interlocutor had been an important learning gain in group work, transferrable to other situations:

(18) I speak a lot slower and clearer and I feel like that's what I do around some of the people in my Mandarin lessons as well. Like, there are people [inaudible], the Chinese woman, things like that, so he can still take...take a few time... a couple of minutes to actually get it in his head to what being said.

In addition, the category of 'working with others', as currently described in the oracy framework, does not take into account the interactive nature of an encounter, even though our data have made it sufficiently clear that individuals have to deal with others' (lack of) communication skills in as much as they have to deal with their own (or the lack thereof), requiring the ability to constantly adapt to changing conditions and crucially, deal with communicative breakdown. This requires complex speaking strategies akin to ELF, as discussed in Section 2.

Finally, it is worth noting that the oracy framework, which was developed to assess the development of speaking skills in secondary school contexts, does not explicitly include the use of a foreign or second language for communication. Oracy is defined as "the development of young peoples' skills in using their first language, or the official / educational language of their country, to communicate across a range of social settings" (Mercer et al., 2017, p. 52). Many of the students who were part of the project reported here were speakers of English as a second or foreign language, and we cannot see any reason as to why the components of 'oracy' should not apply to them.

The repurposing of the framework for research, and for higher education, may well account for some of these weaknesses. Despite these limitations, the oracy framework provides a good basis for mapping out the wide range of speaking demands for specific academic events as wells for integrating an ELF perspective. 


\subsubsection{HE support for speaking demands in group work (and other academic genres)}

In this section, we will discuss how support to develop the speaking demands for academic work is currently structured in Anglophone higher education and how it could be structured and supported in the future. Support for international students is primarily provided through EAP courses and programmes which prepare students for academic study or which run concurrently to academic programmes. On the surface, EAP is inclusive of spoken and written language skills and of native as well as non-native speakers. For example, Hyland \& Shaw (2016) define EAP as "language research and instruction that focuses on the communicative needs and practices of individuals working in academic contexts" (p. 15). However, an overall emphasis on written assignments in degree courses and the fact that entry requirements for programmes often require a higher writing score mean that any lack of accuracy and skill is most evident in writing. In addition, seminars and presentations are more transient and provide more immediate opportunities for negotiation of meaning, making it more difficult to describe the properties of effective spoken language. This means that EAP classes tend to centre around "the type of text they'll have to produce" (Wingate \& Tribble, 2011, p. 489) and that skills akin to ELF which develop students' strategic competence in speaking are rarely systematically attended to.

In this context, it is relevant to observe that scholars in both the ELF and the EAP camps express scepticism in relation to ELF's place in applied pedagogy. For example, prominent ELF scholar Jennifer Jenkins suggests that "it is for ELT practitioners to decide whether / to what extent ELF is relevant for their learners in their context" (Jenkins, 2012, p. 492).

Discussing ELF in relation to EAP writing, Tribble (2017) acknowledges that the native speaker norm resisted by ELF is not ideal for instructional purposes, but favours retaining a genre-based approach and suggests that "a focus on expertise" irrespective of native speaker status and "attention to disciplinary requirements" (p. 40) should be used to support EAP writing instruction. In contrast, Björkman (2011b) shows more optimism about ELF's translatability into EAP 
practice, suggesting that this should include a consideration of norms and standards in the specific context which is the object of instruction, the prioritisation of comprehensibility, and the inclusion of pragmatic strategies for speaking and listening and an inclusion of non-native accents in listening materials. In reality, EAP classes tend to be attended mainly by non-native speakers of English. Additional writing and speaking support outside EAP, which also caters for native speakers, is offered through academic skills support units in which, similarly to EAP, efforts tend to be focussed on writing support. If speaking instruction is offered at all, it normally concentrates on monologic events such as presentations which do not give rise to the interpersonal and language issues described earlier in this paper. For example, the academic support unit in the main author's own institution lists in their 2018/19 Semester 2 programme only one workshop on 'effective presentations', whilst the vast majority of other workshop opportunities centre on writing / dissertations / referencing, and some on critical thinking or exam techniques.

Student support for speaking in UK Higher Education - although we would expect a similar picture in other English-majority countries - thus suffers from a number of shortfalls. As shown above, there is little cocurricular provision adequate to meet the speaking demands outlined above. This is particularly disappointing given requirements for effective academic speaking are also not consistently taught in students' disciplinary studies despite underpinning assessment regimes. For example, a mark may well be based on the written account of a group project, but that written account is produced as a result of face-to- face group meetings, the success of which relies on the broad spectrum of skills described above. For example, Heron (2019), in an analysis of two undergraduate business modules, showed that their content, pedagogy and assessment displayed a "restricted view of the dimensions of oracy skills" (p. 9) with a limited focus in particular on the cognitive dimension.

Secondly, current models of support have allowed an unnatural division between international and home students to emerge and persist, which, as we have argued previously (Dippold et al., 2018), can be hugely damaging. On one hand, international students are singled out as a group in need of support "with the unstated implication that home students 
already have these competences" (Hathaway, 2015, p. 507), whilst on the other, home students resist the support offered to them on grounds that "they are usually framed as addressing a deficiency" (Hathaway, 2015, p. $510)$. Both this paper, using the case of speaking in group work, and Gourlay's (2009) report on undergraduate students' experiences with academic writing at a UK university, have shown that home students also grapple with aspects of speaking and writing skills. On this note, Wingate $\&$ Tribble (2012) argue that

"all students, whether they are native or non-native speakers of English, or 'non-traditional' or 'traditional' students, are novices when dealing with academic discourse [...]. Research-based guidelines and principles are needed to replace the existing instructional provision with a writing pedagogy that caters for all novices" (p. 484).

We emulate these claims, arguing here that a speaking pedagogy, similar to writing, also needs "to be foregrounded [...] rather than left as peripheral (Hathaway 2015: 516). Ideally, this would entail (using Hathaway's terminology) 'mainstreaming' student support by moving explicit speaking instruction into core curricula, in particular when academic success in speaking is crucial to task success. As shown previously, ELF would be able to provide research-based guidelines for such provision, allowing students not only to develop new strategies for negotiating meaning and relationships, but also to discuss issues relating to linguistic identity and their implications in a space shared by native speakers and non-native speakers or international and home students respectively.

Most importantly, a grounding in ELF principles ensures a focus on language as the central tool for dealing with and preventing communicative breakdown. Mainstream HE research, owing to its focus on perceptions of group work and of collaboration and communication in groups, has little to offer in terms of a pedagogical toolkit. In contrast, explicit support in the development of speaking skills for group work, provided outside the formal assessment process and underpinned by recordings and transcripts of actual encounters, will allow all students to reflect, self-assess and develop their strategic repertoire. Given that this investigation as well as other research (Margić, 2017; Wicaksono, 2012) has clearly shown that native and non-native speakers alike need to be 
enabled to make communicative adjustments whilst managing fears of appearing condescending or patronising, we argue that this support is best provided in disciplinary settings (seminars, lectures, tutorials) which include native as well as non-native speakers, thus strengthening dialogue between students who speak different varieties of English from the very start. Integration into disciplinary study is also able to relate speaking to differing disciplinary demands.

With this in mind, ELF needs to overcome its own biases in order to be able to make itself useful to support a speaking pedagogy. Some of the examples presented in this paper have shown that, despite an openly stated willingness to adapt and accommodate, normative assessments of non-native speaker language and communication skills have the potential to impact the interpersonal dynamics in international group work. ELF would thus do well in acknowledging the possible normative role of native speakers and draw on data which includes them. Similarly, HE research would benefit from opening itself up to new approaches to data, research and analysis. Research on student and staff perceptions of and opinions about group work and other learning contexts has made it sufficiently clear that language and communication are at the heart of learning. It is time to start investigating what participants in these contexts actually do rather than what they perceive and think, and the microanalytic tools provided by ELF and other approaches relying on the linguistic and discursive analysis of spoken interaction would provide an ideal starting point.

\section{Conclusions}

This paper has, mirroring Margić (2017), shown that speakers make a conscious effort in negotiating meaning and using language that accommodates group members, in particular non-native speakers. What it has not been able to show was whether speakers' actual communicative behaviours have matched their reports of displayed or desired behaviours. This is of course due to the fact that this paper - contrary to the demands outlined in 5.2.2 - did not draw on authentic communicative group work data in an HE context, the collection of which would have required more funding than was available for this project. However, by focusing the analysis explicitly on speaking demands, we have demonstrated that students are aware of principles of ELF and willing to put them into 
action, and have highlighted the centrality of speaking for academic success.

This provides the basis for future research on the complexity of spoken language in the context of HE group work (and beyond) which can be used to support its development pedagogically, with language and communication being foregrounded. We should not forget that these efforts do not only support group work, but will have effects into employment, supporting graduates when working in international teams to complete high stakes tasks.

An authentic environment for using HE group work to prepare adequately for employment can only be provided if the university community is brought together and specific groups are not singled out based on their enrolment status (home / international student) or their use of English (native / non-native speaker). Using ELF as a vehicle for this entails the potential to, as Price (2009) demands, "[use] the linguistic diversity of the student body [...] as an asset" (p. 36). It is time to take ELF off the shelf and integrate its principles into a speaking pedagogy for all.

\section{Acknowledgments}

The authors wish to thank Marion Heron for her valuable comments on earlier drafts of this paper.

\section{References}

Baker, W., \& Hüttner, J. (2017). English and more: a multisite study of roles and conceptualisations of language in English medium multilingual universities from Europe to Asia. Journal of Multilingual and Multicultural Development, 38(6), 501-516. https://doi.org/10.1080/01434632.2016.1207183

Basturkmen, H., \& Shackleford, N. (2014). How content lecturers help students with language: an observational study of language-related episodes in interaction in first year accounting classrooms. English for Specific Purposes, 37(6), 87-97. https://doi.org/10.1016/j.esp.2014.08.001 
Blaj-Ward, L. (2017). Language learning and use in English-medium higher education. Basingstoke: Palgrave.

Björkman, B. (2011a). English as a lingua franca in higher education: implications for EAP. Iberica, 22, 79-100.

Björkman, B. (2011b.) Pragmatic strategies in English as a Lingua Franca: ways of achieving communiative effectiveness? Journal of Pragmatics, 43(4), 950-964. https://doi.org/10.1016/j.pragma.2010.07.033

Cathart, A., Dixon-Dawson, J., \& Hall, R. (2006). Reluctant hosts and disappointed guests? Examining expectations and enhancing experiences of cross cultural group work on postgraduate business programmes. The International Journal of Management Education, 5(1), 13-22

Celce-Murcia, M., Dörnyei, Z., \& Thurrell, S. (1995). Communicative competence: a pedagogically motivated model with content specifications. Issues in Applied Linguistics, 6(2), 5-35.

Dippold, D. (2013). Interaction for learning in the Anglophone university classroom: Mastering interactional challenges through reflective practice. Journal for Academic Language and Learning, 7(1), A14-A25.

Dippold, D. (2015). Classroom interaction: the internationalised Anglophone university. Basingstoke: Palgrave.

Dippold, D., Bridges, S., Eccles, S. \& Mullen, E. (2018). Developing the global graduate: how first year university students narrate their experiences of culture. Language and Intercultural Communication, 19(4), 313-327. https://doi.org/10.1080/14708477.2018.1526939

Doherty, C., Kettle, M., May, L, \& Caukills, E. (2011). Talking the talk: Oracy demands in first year university assessment tasks. Assessments in Education: Principles, Policy and Practice, 18(1), 27-39. https://doi.org/10.1080/0969594X.2010.498775

Dunne, C. (2009). Host students' perspectives of intercultural contact in an Irish university. Journal of Studies in International Education, 13(2), 307-320. https://doi.org/10.1177/1028315308329787 
Elliot, C., \& Reynolds, M. (2014). Participative pedagogies, group work and the international classroom: an account of students' and tutors' experiences. Studies in Higher Education, 39(2), 307-320.

https://doi.org/10.1080/03075079.2012.709492

Ellis, R. (2003). Task-based language learning and teaching. Oxford:

Oxford University Press.

Duff, P. (2010). Language socialisation into academic discourse communities. Annual Review of Applied Linguistics, 30, 169-192. https://doi.org/10.1017/S0267190510000048

Firth, A. (1996). The discursive accomplishment of normality. On 'lingua franca' English and conversation analysis. Journal of Pragmatics, 26(2), 237-259. https://doi.org/10.1016/0378- 2166(96)00014-8

Gabriel, Y., \& Griffiths, D. (2008). International learning groups: synergies and dysfunctions. Management Learning, 39(5), 503-518. https://doi.org/10.1177/1350507608096038

Glossary of skills (n.d.).

https://www.educ.cam.ac.uk/research/projects/oracytoolkit/oracyskillsfra mework/Glossaryofskills.pdf. Accessed 28 January 2019.

Gourlay, L. (2009). Threshold practices: becoming a student through academic literacies. London Review of Education, 7(2), 181-192. https://doi.org/10.1080/14748460903003626

Hall, D., \& Buzwell, S. (2012). The problem of free-riding in group projects: Looking beyond social loafing as reason for non-contribution. Active Learning in Higher Education, 14(1), 37-49. https://doi.org/10.1177/1469787412467123

Hassaninen, A. (2006). Student experience of group work and group work assessment in Higher Education. Journal of Teaching in Travel \& Tourism, 6(1), 17-39. https://doi.org/10.1300/J172v06n01_02

Hathaway, J. (2015). Developing that voice: locating academic writing tuition in the mainstream of higher education. Teaching in Higher Education, 20(5), 506-517. 
https://doi.org/10.1080/13562517.2015.1026891

Heron, M. (2019). Making the case for oracy skills in higher education: practices and opportunities. Journal of University Teaching and Learning Practice, 16(2).

Hyland, K., \& Shaw, P. (2016). Introduction. In K. Hyland \& P. Shaw (Eds.), The Routledge Handbook of English for Academic Purposes (pp. 1-13). London: Routledge.

Hua, Z. (2015). Negotiation as the way of engagement in intercultural and lingua franca communication: Frames of reference and interculturality. Journal of English as a Lingua Franca, 4(1), 63-90. https://doi.org/10.1515/jelf-2015-0008

Ippolito, K. (2007). Promoting intercultural learning in a multicultural university: Ideals and realities. Teaching in Higher Education, 12(5-6), 749-763. https://doi.org/10.1080/13562510701596356

Jenkins, J. (2012). English as a lingua franca from the classroom to the classroom. ELT Journal, 66(4), 486-494. https://doi.org/10.1093/elt/ccs040

Komori-Glatz, M. (2017). (B)ELF in multicultural student teamwork. Journal of English as a lingua franca, 6(1), 83-109.

https://doi.org/10.1515/jelf-2017-0007

Komori-Glatz, M. (2018). "Cool my doubt is erased": constructive disagreement and creating a psychologically safe space in multicultural student teamwork. Journal of English as a lingua franca, 7(2), 285-306. https://doi.org/10.1515/jelf-2018-0012

Margić, B. (2017). Communication courtesy or condescension? Linguistic accommodation of native to non-native speakers of English. Journal of English as a lingua franca, 6(1), 29-55. https://doi.org/10.1515/jelf-20170006

Mauranen, A. (2012). Exploring ELF. Academic English shaped by nonnative speakers. Cambridge: Cambridge University Press. 
Mercer, N., Warwick, P., \& Warwick, A. (2017). An oracy assessment toolkit: linking research and development in the assessment of students' spoken language skills at age 11-12. Learning and Instruction, 48, 51-60. https://doi.org/10.1016/j.learninstruc.2016.10.005

Montgomery, C. (2009). A decade of internationalisation: has it influenced students' views of cross- cultural groupwork at university? Journal of Studies in International Education, 13(3), 256-270. https://doi.org/10.1177/1028315308329790

Peacock, N., \& Harrison, N. (2009). "It's so much easier to go with what's easy": Mindfulness and the discourse between home and international students in the United Kingdom. Journal of Studies in International Education, 13(4), 487-508. https://doi.org/10.1177/1028315308319508

Popov, V., Brinkman, D., Biemans, H., Mulder, M., Kuvnetsov, A., \& Noroovi, O. (2012). Multicultural student group work in higher education: an explorative case study on challenges as perceived by students. International Journal of Intercultural Relations, 36(2), 302-317. https://doi.org/10.1016/j.ijintrel.2011.09.004

Preece, S. (2009). Multilingual identities in higher education: negotiating the 'mother tongue', 'posh' and 'slang'. Language and Education, 24(1), 21-39. https://doi.org/10.1080/09500780903194036

Prince, M. (2004). Does active learning work? A review of the research. Journal of Engineering Education, 93(3), 223-231.

https://doi.org/10.1002/j.2168-9830.2004.tb00809.x

Robinson, S. (2006). Reflecting on the 'International group working experience': A study of two MBA programmes. International Journal of Management Education, 5(2), 3-13.

Robles, M. (2012). Executive perceptions of the top 10 soft skills needed in today's workplace. Business Communication Quarterly, 75(4), 453465. https://doi.org/10.1177/1080569912460400

Ryan, J., \& Viete, R. (2009). Respectful interactions: Learning with international students in the English- speaking academy. Teaching in 
Higher Education, 14(3), 303-314.

https://doi.org/10.1080/13562510902898866

Seidlhofer, B. (2001). Closing a conceptual gap: the case for a description of English as a Lingua Franca. International Journal of Applied Linguistics, 11(2), 133-158.

Soetano, D., \& MacDonald, M. (2017). Group work and the change of obstacles over time: the influence of learning style and group composition. Active Learning in Higher Education, 18(2), 99-113. https://doi.org/10.1177/1469787417707613

Spencer-Oatey, H., \& Dauber, D. (2017). The pains and gains of mixed national group work at university. Journal of Multilingual and Multicultural Development, 38(3), 219-236.

https://doi.org/10.1080/01434632.2015.1134549

Toomaneejinda, A., \& Harding, L. (2018). Disagreement practices in ELF academic group discussion: verbal, nonverbal and interactional strategies. Journal of English as a Lingua Franca, 7(2), 307-332.

https://doi.org/10.1515/jelf-2018-0016

Tribble, C. (2017). ELFA vs. genre: a new paradigm war in EAP writing instruction? Journal of English for Academic Purposes, 25, 30-44.

https://doi.org/10.1016/j.jeap.2016.10.003

Turner, Y. (2009). Knowing me, knowing you, is there nothing we can do? Pedagogic challenges in using group work to create an intercultural learning space. Journal of Studies in International Education, 13(2), 240255. https://doi.org/10.1177/1028315308329789

Volet, S. \& Ang, G. (1998). Culturally mixed groups on international campuses: an opportunity for inter- cultural learning. Higher Education Research and Development, 31(1), 21-37. https://doi.org/10.1080/0729436980170101

Wicaksono, R. (2012). Accommodating understanding in English: an applied linguistic analysis of UK and international students navigating TESOL tasks. University of London: London, UK. 
Wingate, U. (2015). Academic literacy and student diversity: the case for inclusive practice. Bristol: Multilingual Matters.

Wingate, U., \& Tribble, C. (2012). The best of both worlds? Towards an English for Academic Purpose / Academic Literacies writing pedagogy. Studies in Higher Education, 37(4), 481-495. https://doi.org/10.1080/03075079.2010.525630 